\title{
Effects of Post-Surgical Parenteral Nutrition on Patients with Gastric Cancer
}

\author{
Yanchun Jin ${ }^{\mathrm{a}}$ Chunming Yong ${ }^{\mathrm{b}}$ Keyu Ren ${ }^{\mathrm{a}}$ Dan Li ${ }^{\mathrm{a}} \quad$ Hao Yuan ${ }^{\mathrm{a}}$ \\ a Department of Gastroenterology, The Affiliated Hospital of Qingdao University, Qingdao, 'Department \\ of Emergency Internal Medicine, The Affiliated Hospital of Qingdao University, Qingdao, China
}

\section{Key Words}

Gastric cancer - Parenteral nutrition - QoL - Anxiety - Depression - Immune function • Malnutrition

\begin{abstract}
Background/Aims: In this study, we investigated the effect of post-surgical parenteral nutrition on patients with gastric cancer (GC) and its possible mechanism. Methods: A total of 108 patients were invited to assess for eligibility and 28 patients were excluded. The eighty patients were randomized to either a study group ( $1 \mathrm{~L}$ peripheral intravenous nutrition, 700 $\mathrm{kcal})$ or a control group ( $1 \mathrm{~L}$ isotonic electrolyte solution). Parenteral nutrition was started on day 1 post-surgery and maintained for 4-8 days. Levels of albumin (ALB), prealbumin $(P A B)$, hemoglobin $(\mathrm{Hb})$ were measured before and after treatment. Self-rating Scale of Life Quality (SSLQ) and Quality of life (QoL) was assessed to analyze the patients' quality of life. Psychological status was evaluated using both the Hospital Anxiety and Depression Scale (HADS-A/D) and the Patient Health Questionnaire-9 (PHQ-9). Immune function was evaluated by flow cytometric analysis of the levels of $\mathrm{CD} 3+, \mathrm{CD} 4+$, and $\mathrm{CD} 8+$ cells. Results: Following post-surgical parenteral nutrition, the levels of $A L B, P A B$ and $\mathrm{Hb}$ were significantly higher in the study group than those in the control group. QoL and SSLQ scores were also significantly increased, while HAD-A/D and PHQ-9 scores were significantly reduced. Furthermore, the percentages of $\mathrm{CD} 3+$ and $\mathrm{CD} 4+$ cells, but not CD8+ cells, as well as the CD4+/CD8+ ratio were significantly increased in the study group. There were no significant differences in these parameters between the control and study group prior to surgery. Conclusion: The results suggest that post-surgical parenteral nutrition can significantly improve the nutritional and psychological status, QoL, and immune function of patients treated surgically for GC.
\end{abstract}

(C) 2018 The Author(s)

Published by S. Karger AG, Basel

\section{Introduction}

Despite the recent decrease in the incidence of gastric cancer (GC), this malignancy remains a leading cause of cancer deaths. In 2012, GC was reported to represent $8.8 \%$ of total cancer deaths worldwide, with a particularly mortality rate on Eastern Asia (mainly 
China) [1]. Due to the low 5-year survival rates, treatment of GC is a significant challenge [2, 3].

Many cases of GC are diagnosed at an advanced stage, when the disease can be complicated by impaired absorption of essential nutrients. Thus, patients with advanced GC, and particularly those treated surgically, are at increased risk of malnutrition, which impacts negatively on immune system function, tumor recurrence and metastasis [4]. Malnutrition in patients is associated with adverse clinical outcomes such as increased period of hospitalization and poor prognosis as well as a reduction in the quality of life (QoL) and psychological status of patients $[5,6]$.

Nutritional support, which can be delivered via the oral, enteral (gastrointestinal) or parenteral (intravenous) is recommended for patients with GC at high risk of malnutrition [7]. Parenteral nutrition is an invasive therapy that provides intravenous nutritional support for individuals without who do not have adequate gastrointestinal functions, such as those with advanced GC [8]. In patients with advanced cancer, parenteral nutrition has been shown to improve nutritional and functional status as well as quality of life (QoL), irrespective of the tumor type [9]; however, the mechanisms underlying these effects remain to be fully elucidated.

The immune dysfunction has been reported to be aggravated by surgical trauma [10]. The activities of $\mathrm{CD} 3+, \mathrm{CD} 4+$, and $\mathrm{CD} 4+/ \mathrm{CD} 8+$ are frequently used to evaluate the immune function [11]. It has been reported that CD4+ and CD8+ cells show synergistic functions in humoral and cellular immunity, effectively maintaining cellular immune function [12-14]. CD4+ could increase the differentiation of B cells to generate antibodies, whereas CD8+ could decrease the differentiation of $\mathrm{T}$ cells and production of antibodies [12]. Therefore, the number of CD3+, CD4+ and CD8+ cells were evaluated between the two groups.

In this study, we investigated the effect of post-surgical parenteral nutrition on patients undergoing gastrointestinal tract surgery for GC and the possible mechanism underlying these effects.

\section{Materials and Methods}

\section{Ethics approval and consent to participate}

The study protocol was reviewed and approved by our Institutional Ethical Committee. The nature and purpose of the study were explained to the subjects and a written informed consent form was signed by all participants before inclusion. All procedures were performed in accordance with the Declaration of Helsinki (1975, revised 1983).

\section{Patients and study design}

Patients scheduled for elective major gastrointestinal tract surgery for GC were enrolled in the study. A total of 108 patients were invited to participate and assessed for eligibility. After excluding individuals who did not meet the inclusion criteria $(n=22)$ or who declined to participate $(n=6)$, eighty patients were randomized to either a study group (1 L peripheral intravenous nutrition, $700 \mathrm{kcal}$ ) or a control group (1L isotonic electrolyte solution). Parenteral nutrition was started on day 1 post-surgery and maintained for 4-8 days ( 4 days for 2 patients, 5 days for 8 patients, 6 days for 7 patients, 7 days for 10 patients and 8 days for 13 patients) according to the clinical stability of the patient.

Exclusion criteria were: (1) preoperative enteral or parenteral nutrition support; (2) organ failure (renal, respiratory, heart, liver); (3) diabetes mellitus type 1 or 2; (4) ongoing infection; (5) biological evidence of inflammation and/or sepsis; (6) current treatment with corticosteroids, nonsteroidal antiinflammatory or immunosuppressive drugs; (7) contraindications for parenteral nutrition (any state of shock, serum lactate $>3-4 \mathrm{mmol} / \mathrm{L}$, hypoxia $\left(\mathrm{pO}_{2}<50 \mathrm{mmHg}\right)$, severe acidosis $\left(\mathrm{pH}<7.2, \mathrm{pCO}_{2}>80 \mathrm{mmHg}\right)$.

Intervention and oral food intake

Parenteral nutrition was administered by a peripheral-venous route. The study group received $1 \mathrm{~L}$ Olimel peri 2.5\%® (Baxter Germany GmbH Medication Delivery, Unterschleißheim, Germany containing 


\section{Cellular Physiology Cell Physiol Biochem 2018;49:1320-1328 and Biochemistry Published online: 12 September, $2018 \begin{aligned} & \text { DOI: 10.1159/000493410 } 2018 \text { The Author(s). Published by S. Karger AG, Basel } \\ & \text { www.karger.com/cpb }\end{aligned}$}

Jin et al.: Parenteral Nutrition in Gastric Cancer

$700 \mathrm{kcal}, 25.3 \mathrm{~g}$ protein, $30.0 \mathrm{~g}$ fat and $75.0 \mathrm{~g}$ glucose). In addition, the study group received an adapted supplementation of vitamins (Cernevit ${ }^{\circledR}$, Baxter) and trace elements (Inzolen ${ }^{\circledR}$ Köhler Pharma GmbH, Alsbach-Haehnlein, Germany). The control group received $1 \mathrm{~L}$ of isotonic fluid (E153, Berlin-Chemie AG, Berlin, Germany). This represents a balanced electrolyte solution for intravenous infusion treatment of isotonic and hypotonic fluid loss. Intravenous access was closely monitored during parenteral nutrition support. In addition, local conditions, such as bleeding, pain, exudates, swelling, and/or induration, were carefully recorded. Moreover, the patients should avoid being wet and overloaded. Furthermore, every patient was asked to keep a food diary during their hospital stay. A nutritionist instructed the patients how to record their food and oral supplementation. The food diaries were analyzed with the OptiDiet ${ }^{\circledR}$ software package (GOE GmbH, Linden, Germany).

\section{Nutritional surveillance}

Blood samples were drawn and laboratory variables (albumin (ALB), prealbumin (PAB), hemoglobin $(\mathrm{Hb})$ ) were measured before and after the administration of parenteral nutrition.

\section{Quality of Life}

In the present study, QoL rating scale and Self-rating Scale of Life Quality (SSLQ) were used to evaluate patients' quality of life before and after the administration of parenteral nutrition. QoL was measured using the European Organization for Research and Treatment of Cancer Quality of Life Questionnaire (EORTCQLQC30). The EORTC QLQ-C30 (version 3.0) is a multidimensional validated cancer-specific measuring method that consists of 30 questions: 15 domains include 5 functional scales (physical functioning (PF); social functioning (SF); emotional functioning (EF); role functioning (RF) and cognitive functioning (CF)), 3 symptom scales (fatigue, pain and nausea/vomiting), 6 single items (appetite loss, dyspnea, diarrhea, insomnia, constipation and financial difficulties), and global health status or QoL scale. Patients rate their functional scales and symptom scales using a 4-point scale (1, not at all; 2, a little; 3, quite a bit and 4, very much). The global health status is evaluated using a 7-point Likert scale (ranging from 'poor' to 'excellent'). All of the scales and single-item measures range from 0 to 100, with a higher score indicating a higher QoL. The QoL scores were calculated according to the scoring manual [15].

SSLQ was a widely used scale of life quality for in-patient with carcinoma in China [16]. There are 24 items with 4 alternative answers in each item. For example, "my understanding of cancer: A, treatable; B, hopeful cure; C, basically an incurable disease; and D, incurable disease." The patient chooses the answer according to his or her own experience. The scores were recorded as 4, 3, 2 and 1 for A-D, respectively. The total scores for all 24 questions were used as an indicator of quality of life.

\section{Psychological status}

Psychological distress was evaluated using the 14-item Chinese version of the Hospital Anxiety and Depression Scale (HADS), which uses a four-point (0-3) Likert scale to assess responses to two seven-item subscales that assess anxiety (HADS-Anxiety) and depression (HADS-Depression). The possible range of scores for each subscale is $0-21$, with higher scores indicating greater levels of anxiety or depression. The Chinese version of both subscales HADS-Anxiety (Cronbach's $\alpha=0.86$ ) and HADS-Depression (Cronbach's $\alpha=0.82$ ) demonstrate good psychometrics [17]. All measurements were obtained at baseline, except for the HADS-A and HADS-D scores, which were assessed at both baseline and 3 months post-baseline. Sociodemographic data including age, marital status, education level, occupation, and family income were also collected during the interview. Medical data were collected from medical records.

Mood was assessed with the use of both the Hospital Anxiety and Depression Scale (HADS) and the Patient Health Questionnaire-9 (PHQ-9).

The 14-item HADS is used to screen for symptoms of anxiety (HADS-A) and depression (HADS-D) in the previous week. Subscale scores range from 0, indicating no distress, to 21, indicating maximum distress; a score higher than 7 on either HADS subscale is considered to be clinically significant [17].

The PHQ-9 is a tool that allows criteria-based assessment of depression based on the responses to a self-administered nine-item module [18]. Each of the items is scored on the incidence of depressive symptoms from 0 (not at all) to 3 (nearly every day); thus, the severity of depression is scored in the range from 0 to 27.

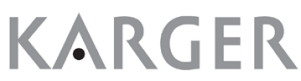




\section{Cellular Physiology Cell Physiol Biochem 2018;49:1320-1328 \begin{tabular}{ll|l} 
and Biochemistry & $\begin{array}{l}\text { DOI: 10.1159/000493410 } \\
\text { Published online: 12 September, } 2018\end{array}$ & $\begin{array}{l}\text { C } 2018 \text { The Author(s). Published by S. Karger AG, Basel } \\
\text { www.karger.com/cpb }\end{array}$ \\
\hline
\end{tabular}

\section{Immunological parameters}

The immune function of patients was evaluated by flow cytometric analysis of the levels of CD3+, CD4+, and CD8+ cells.

\section{Statistical analysis}

Statistical analyses were performed with the use of SPSS software, version 16.0 (SPSS). Descriptive statistics were used to estimate the frequency and mean \pm standard deviation (SD) of the study variables. Differences between study groups in baseline characteristics and clinical outcomes were assessed using the two-sided Fisher's exact tests and chi-square tests for categorical variables and independent-samples. Student's $t$-tests were used to analyze continuous variables. Multivariate linear regression analyses adjusted for baseline scores were used to examine the effect of early palliative care on QoL outcomes. $P<0.05$ was considered to indicate statistical significance.

\section{Results}

Comparison of demographic variables of control and study groups

A flow diagram of the study protocol is presented in Fig. 1. Patients' demographic data are presented in Table 1 . A total of 80 patients were recruited into the study. The patients were randomly assigned to the control and study groups ( $\mathrm{n}=40$ in each group). The control group comprised 11 women (27.5\%) and 29 men (72.5\%), with a mean age of 62.4 years \pm 5.35 years. The study group comprised 10 women $(25.0 \%)$ and 30 men (75\%), with a mean age of $63.6 \pm 5.28$ years. There were no significant differences in sex, age, hospitalization period, education, surgical procedures (total and subtotal gastrectomy) and degree of comprehension of illness between the two groups.

Effect of post-surgical parenteral nutrition on nutritional status of patients with GC

To determine the effects of post-surgical parenteral nutrition on the nutritional status of the patients with $\mathrm{GC}$, the levels of ALB, PAB and $\mathrm{Hb}$ analyzed in blood samples obtained before and after treatment (Fig. 2A-2C, respectively). There were no significant differences in ALB, $\mathrm{PAB}$ and $\mathrm{Hb}$ levels between the control and study groups before treatment. However, after parenteral nutrition, the levels of ALB, PAB and $\mathrm{Hb}$ were significantly higher in the study group compared with those in the control group $(P<0.05)$.

Effect of post-surgical parenteral nutrition on quality of life of patients with $G C$

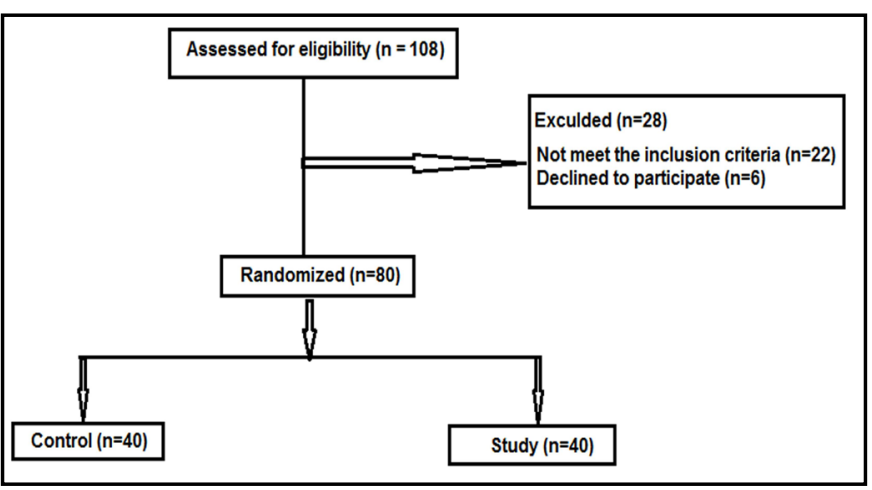

Fig. 1. CONSORT 2010 flow diagram of the trial.

Table 1. Baseline characteristics of control and study participants

\begin{tabular}{|c|c|c|c|c|}
\hline Group variables & & Control $(\mathrm{n}=40)$ & Study $(\mathrm{n}=40)$ & $\mathrm{P}$ \\
\hline \multirow[t]{3}{*}{ Sex } & & & & 0.78 \\
\hline & Male & $11(27.5 \%)$ & $10(25.0 \%)$ & \\
\hline & Female & $29(72.5 \%)$ & $30(75.0 \%)$ & \\
\hline Ages (years) & & $62.4 \pm 5.35$ & $63.6 \pm 5.28$ & 0.46 \\
\hline Hospitalization (days) & & $10.6 \pm 1.3$ & $9.9 \pm 1.8$ & 0.82 \\
\hline \multirow[t]{5}{*}{ Education } & & & & 0.77 \\
\hline & Illiterate & $1(2.5 \%)$ & $2(5.0 \%)$ & \\
\hline & Primary school & $19(47.5 \%)$ & $18(45.0 \%)$ & \\
\hline & High school & $14(35.0 \%)$ & $13(32.5 \%)$ & \\
\hline & University & $6(15.0 \%)$ & $7(17.5 \%)$ & \\
\hline \multirow[t]{3}{*}{ Surgical procedures } & & & & 0.82 \\
\hline & Total gastrectomy & $26(65 \%)$ & $25(62.5 \%)$ & \\
\hline & Subtotal gastrectomy & $14(35 \%)$ & $15(37.5 \%)$ & \\
\hline \multirow[t]{4}{*}{ Comprehension of illness } & & & & 0.91 \\
\hline & No knowledge of illness/prognosis & $12(30.0 \%)$ & $11(27.5 \%)$ & \\
\hline & Aware of diagnosis but not prognosis & $14(35.0 \%)$ & $15(37.5 \%)$ & \\
\hline & Fully aware of diagnosis/prognosis & $14(35.0 \%)$ & $14(35.0 \%)$ & \\
\hline
\end{tabular}




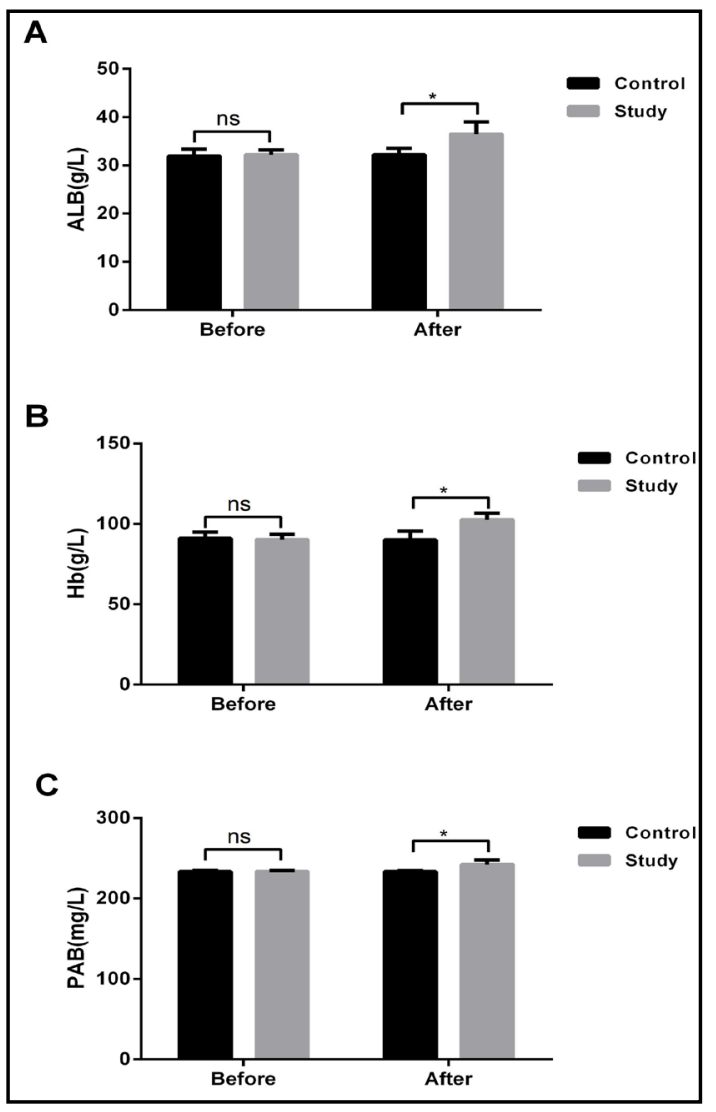

Fig. 2. Effect of parenteral nutrition on nutritional status of patients with GC.To determine the effects of parenteral nutrition on the nutritional status of the patients with GC, the levels of (A) albumin (ALB), (B) prealbumin (PAB) and (C) hemoglobin ( $\mathrm{Hb})$ analyzed in blood samples obtained before and after treatment. ns, no significant difference; ${ }^{*} \mathrm{P}<0.05$.

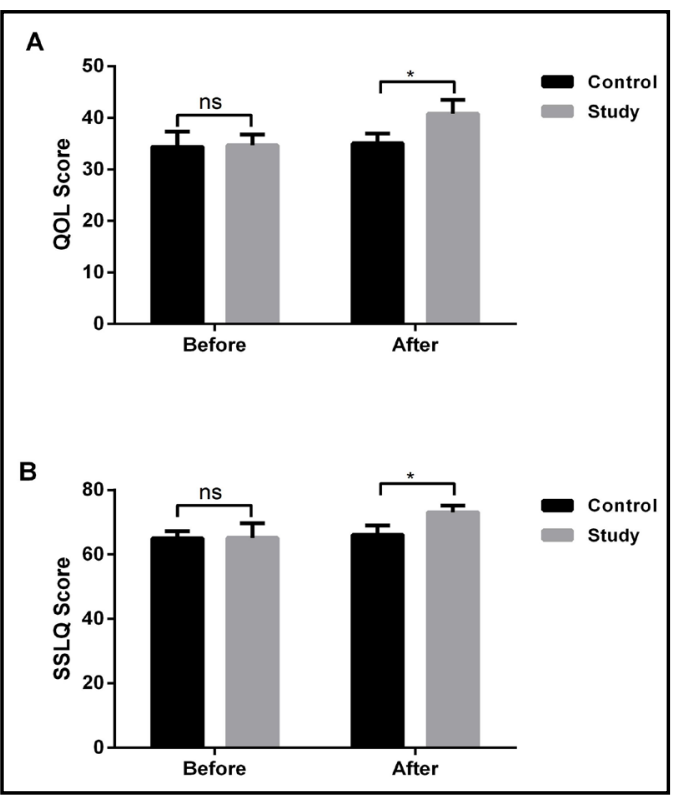

Fig. 3. Effect of parenteral nutrition on quality of life of patients with GC.The effects of parenteral nutrition on quality of life were analyzed by determining the (A) QoL and (B) SSLQ scores using the European Organization for Research and Treatment of Cancer Quality of Life Questionnaire (EORTC-QLQC30). ns, no significant difference; $* \mathrm{P}<0.05$.

The effects of post-surgical parenteral nutrition on quality of life were analyzed by determining the QoL and SSLQ scores (Fig. 3A and 3B, respectively). Analysis of the QoL and SSLQ scores showed that there were no significant differences between the control and study groups before the intervention. After parenteral nutrition, QoL and SSLQ scores were significantly higher in the study group compared with those in the control group $(P<0.05)$.

\section{Effect of post-surgical parenteral nutrition on psychological status of patients with GC}

The effects of post-surgical parenteral nutrition on the psychological status of patients were evaluated using both the Hospital Anxiety and Depression Scale (HADS-A and HADS-D) and the Patient Health Questionnaire-9 (PHQ-9). Compared with the control group, significant reductions in the HAD-D (Fig. 4A; $P<0.01$ ), HAD-A (Fig. 4B; $P<0.05$ ) and PHQ-9 (Fig. 4C; $P<0.01$ ) scores were observed in the study group.

\section{Effect of post-surgical parenteral nutrition on immune function of patients with GC}

The effects of post-surgical parenteral nutrition on immune function were investigated by flow cytometric analysis of the proportions of CD3+ (Fig. 5A), CD4+ (Fig. 5B), CD8+ (Fig. 5C) and CD4+/CD8+ (Fig. 5D) populations in PBMC isolated from blood samples obtained after treatment. The results showed that the percentages of CD3+ and CD4+ were significantly increased after parenteral nutrition compared to those in the control group (both $P<0.05$ ), 
while there was no significant difference in the percentage of CD8+ cells between the two groups. Furthermore, there was a significant increase in the ratio of $\mathrm{CD} 4+$ / CD8+ in the study group compared to that in the control group $(P<0.05)$.

\section{Discussion}

In this study, we investigated the effect of post-operative parenteral nutrition in patients with gastric cancer scheduled for elective major gastrointestinal tract surgery. We found that parenteral nutrition significantly improved the nutritional status and immune function of these patients. Furthermore, this strategy was associated with improved psychological status and QoL, indicating the benefits of parenteral nutrition for patients treated surgical for advanced GC.

It has been well acknowledged that malnutrition always results in immunosuppression. Consequently, parenteral nutrition or parenteral nutrition combined with enteral nutrition is necessary to maintain the nutritional status for patients with advanced cancer, including gastric cancer $[19,20]$, during oncologic treatment to improve nutritional and functional status, QoL and prognosis [21]. Although increasing evidence suggests that early enteral nutrition (EEN) is better than parenteral nutrition in severe injury or other post-operative cancer treatment, no significant difference was found in EEN and parenteral nutrition after total gastrectomy in patients with gastric cancer [22]. Hence, parenteral nutrition is the only option

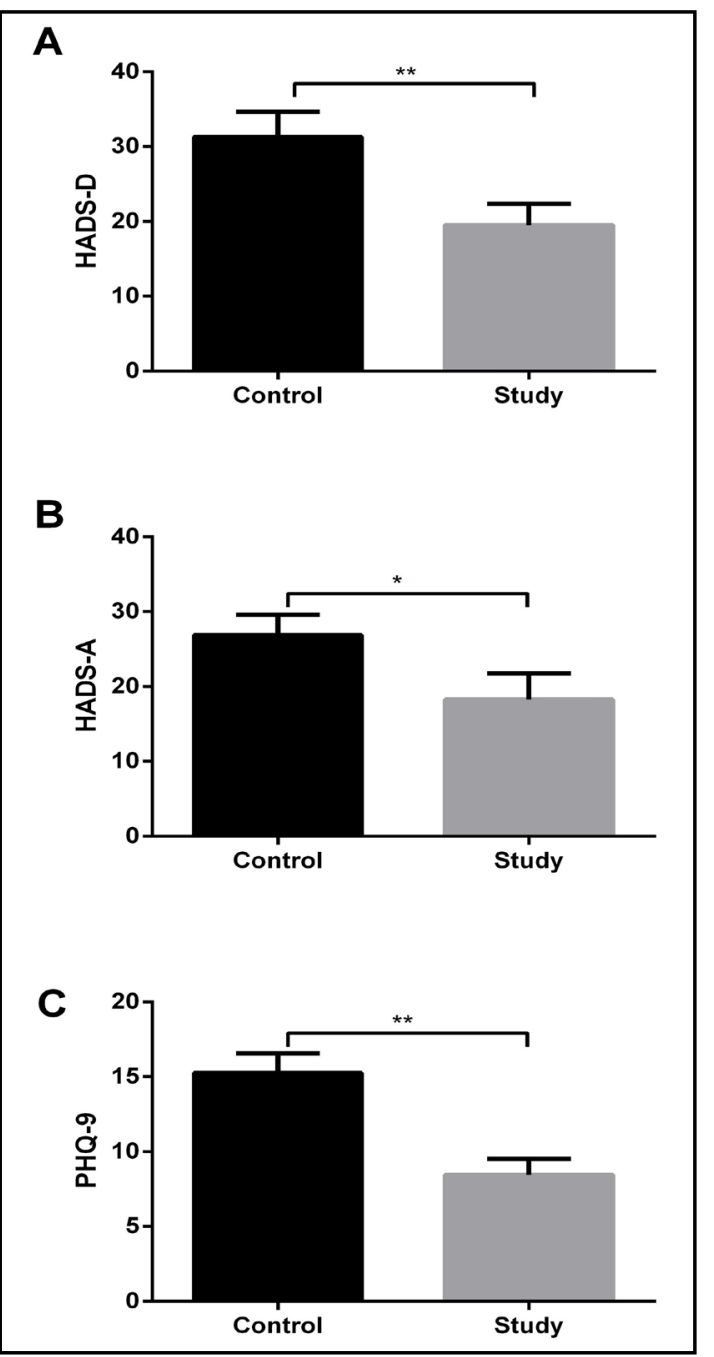

Fig. 4. Effect of parenteral nutrition on psychological status of patients with GC. The effects of parenteral nutrition on the psychological status of patients were evaluated using both the Hospital Anxiety and Depression Scale [(A) HADS-D and (B) HADS-A] and (C) the Patient Health Questionnaire-9 (PHQ-9). ns, no significant difference; ${ }^{*} \mathrm{P}<0.05 ;{ }^{* *} \mathrm{P}<0.01$. for patients with advanced GC who are not suitable for oral or enteral nutritional support. However, the exact mechanism underlying the parenteral nutrition is still unclear. Therefore, in the present study, we explored the effects of post-surgical parenteral nutrition on patients with gastric cancer, as well as the potential mechanism(s).

A total of 80 patients who met the inclusion criteria were finally included. Among the 80 patients, there were no significant differences in sex, age, hospitalization period, education, surgical procedures and degree of comprehension of illness between the study and control groups, which implied the comparable results. Next, we assigned these patients to study or control group. Thereafter, nutritional or immune indicators were compared before and/ or after the parenteral nutritional. As shown in the results, we found that there were no significant differences in ALB, PAB and $\mathrm{Hb}$ levels between the control and study groups prior to treatment, suggesting the similar nutritional status among the patients. However, the levels of ALB, PAB and Hb were significantly higher in the study group compared with 


\section{Cellular Physiology Cell Physiol Biochem 2018;49:1320-1328 and Biochemistry Published online: 12 September, $2018 \begin{aligned} & \text { DOI: 10.1159/000493410 } 2018 \text { The Author(s). Published by S. Karger AG, Basel } \\ & \text { www.karger.com/cpb }\end{aligned}$ Jin et al.: Parenteral Nutrition in Gastric Cancer}

those in the control group after receiving parenteral nutrition. These results showed that parenteral nutrition could improve the protein metabolism and neurological function and decline negative nitrogen, indicating the benefit of post-operative parenteral nutrition on the nutritional status of patients with GC. Our results were in consistence with a longitudinal study, in which the results showed that home-delivered parenteral nutrition was associated with improved nutritional status, regardless of the tumor type [9].

QoL has become a critical outcome for evaluating the treatment effects in cancer patients [23]. In addition, the prevalence of anxiety and depression are often described in the cancer patients. Therefore, we further addressed the question whether post-operative parenteral nutrition has benefit effects on QoL and psychological status of patients. The results demonstrated that there were no significant differences in QoL and SSLQ scores between the study and control groups prior to the intervention. However, after the administration of post-operative parenteral nutrition, the QoL and SSLQ scores were both significantly higher in the study group, indicating the benefits of this intervention on the QoL of these patients. Similarly, significant reductions in the HAD-D, HAD-A and PHQ-9 scores in the study group compared with those in the control group provide evidence that parenteral nutrition improves the psychological status of patients.

In combination, these results clearly indicated that parenteral nutrition not only improves the nutritional status of patients with GC following major gastrointestinal tract surgery, but also offers benefits in terms of improved psychological status and QoL. However, the mechanism underlying the positive effects is unclear. It has been well acknowledged that the development, maintenance, and response of the immune system are affected by nutrition [24]. Achieving the established requirements for consumption and supply is a significant nutritional strategy for optimizing immunity [25]. Severe nutritional inadequacie of required nutrients may typically impair the host immunity and resistance to disease. Leukocytes, especially $\mathrm{T}$ lymphocytes, however, are very sensitive to marginal deficiencies of several essential nutrients [25]. Therefore, in this study, we investigated the effect of parenteral nutrition on immunity by monitoring the levels of CD3+,CD4+ and CD8+ cells in the peripheral blood of patients before and after the intervention. The results showed that the percentages of CD3+ and CD4+ were significantly increased after parenteral nutrition compared to those in the control group, while there was no significant difference in the percentage of CD8+ cells between the two groups. Furthermore, there was a significant increase in the ratio of CD4+/CD8+ in the study group compared to that in the control group. These observations indicate that parenteral nutrition enhances $\mathrm{CD} 4+\mathrm{T}$ cell immune responses, which may be involved in the beneficial effects of this intervention in GC patients. However, further studies are required to fully elucidate the effects of parenteral nutrition on immunity. Nevertheless, 


\section{Cellular Physiology Cell Physiol Biochem 2018;49:1320-1328 \begin{tabular}{ll|l} 
and Biochem 10.1159/000493410 & $\begin{array}{l}\text { @ } 2018 \text { The Author(s). Published by S. Karger AG, Basel } \\
\text { www.karger.com/cpb }\end{array}$ \\
\hline
\end{tabular}

previous studies have shown that modification of the composition of parenteral nutrition may be a suitable approach to improving post-operative clinical outcomes in patients with GC. For instance, a recent study showed that high-calorie/protein supplementation with the immune-modulating diet was able to maintain the nutrition and immune status of patients with GC [26]. Furthermore, a study conducted in a population of elderly patients who underwent surgery for GC showed that the combination of enteral and parenteral nutrition was superior to either early enteral nutrition or total parenteral nutrition in promoting the recovery of immunity [27]. Thus, modification of the nutrient composition or combining routes of administration may be effective approaches to improving post-operative clinical outcomes in patients with GC.

The limitations of this study should be noted. Although we measured the effects of parenteral nutrition on markers of nutritional status, we did not evaluate changes in physiological factors such as body weight and body mass index, as well as different domains that might affect the patients' health status. In addition, further studies are required to confirm and validate our results indicating that parenteral nutrition enhanced CD4+ T cell immune responses and also to validate our findings in other populations.

In conclusion, our results show that post-surgical parenteral nutrition can significantly improve the nutritional status and immune function in patients with GC.

\section{Disclosure Statement}

The authors have no financial conflicts of interest.

\section{References}

1 Ferlay J, Soerjomataram I, Dikshit R, Eser S, Mathers C, Rebelo M, Parkin DM, Forman D, Bray F: Cancer incidence and mortality worldwide: sources, methods and major patterns in GLOBOCAN 2012. Int J Cancer 2015;136:E359-386.

-2 De Angelis R, Sant M, Coleman MP, Francisci S, Baili P, Pierannunzio D, Trama A, Visser O, Brenner H, Ardanaz E, Bielska-Lasota M, Engholm G, Nennecke A, Siesling S, Berrino F, Capocaccia R: Cancer survival in Europe 1999-2007 by country and age: results of EUROCARE--5-a population-based study. Lancet Oncol 2014;15:23-34.

3 Zheng R, Zeng H, Zhang S, Chen T, Chen W: National estimates of cancer prevalence in China, 2011. Cancer Lett 2016;370:33-38.

4 Gomez F, Ramos Galvan R, Frenk S, Cravioto Munoz J, Chavez R, Vazquez J: Mortality in second and third degree malnutrition. 1956. Bull World Health Organ 2000;78:1275-1280.

5 Correia MI, Waitzberg DL: The impact of malnutrition on morbidity, mortality, length of hospital stay and costs evaluated through a multivariate model analysis. Clin Nutr 2003;22:235-239.

6 Lim SL, Ong KC, Chan YH, Loke WC, Ferguson M, Daniels L: Malnutrition and its impact on cost of hospitalization, length of stay, readmission and 3-year mortality. Clin Nutr 2012;31:345-350.

-7 Arends J, Bachmann P, Baracos V, Barthelemy N, Bertz H, Bozzetti F, Fearon K, Hutterer E, Isenring E, Kaasa S, Krznaric Z, Laird B, Larsson M, Laviano A, Muhlebach S, Muscaritoli M, Oldervoll L, Ravasco P, Solheim T, Strasser F, et al.: ESPEN guidelines on nutrition in cancer patients. Clin Nutr 2017;36:11-48.

-8 Bozzetti F, Arends J, Lundholm K, Micklewright A, Zurcher G, Muscaritoli M: ESPEN Guidelines on Parenteral Nutrition: non-surgical oncology. Clin Nutr 2009;28:445-454.

-9 Vashi PG, Dahlk S, Popiel B, Lammersfeld CA, Ireton-Jones C, Gupta D: A longitudinal study investigating quality of life and nutritional outcomes in advanced cancer patients receiving home parenteral nutrition. BMC Cancer 2014;14:593.

10 Menges P, Kessler W, Kloecker C, Feuerherd M, Gaubert S, Diedrich S, van der Linde J, Hegenbart A, Busemann A, Traeger T, Cziupka K, Heidecke CD, Maier S: Surgical trauma and postoperative immune dysfunction. Eur Surg Res 2012;48:180-186. 


\section{Cellular Physiology Cell Physiol Biochem 2018;49:1320-1328 and Biochemistry Published online: 12 September, $2018 \begin{aligned} & \text { DOI: } 2018 \text { The Author(s). Published by S. Karger AG, Basel } \\ & \text { www.karger.com/cpb }\end{aligned}$ \\ Jin et al.: Parenteral Nutrition in Gastric Cancer}

11 Feng F, Ji G, Li JP, Li XH, Shi H, Zhao ZW, Wu GS, Liu XN, Zhao QC: Fast-track surgery could improve postoperative recovery in radical total gastrectomy patients. World J Gastroenterol 2013;19:3642-3648.

12 Li B, Liu HY, Guo SH, Sun P, Gong FM, Jia BQ: The postoperative clinical outcomes and safety of early enteral nutrition in operated gastric cancer patients. J BUON 2015;20:468-472.

13 Elliott JA, Patel VM, Kirresh A, Ashrafian H, Le Roux CW, Olbers T, Athanasiou T, Zacharakis E: Fast-track laparoscopic bariatric surgery: a systematic review. Updates Surg 2013;65:85-94.

14 Jones NE, Heyland DK: Implementing nutrition guidelines in the critical care setting: a worthwhile and achievable goal? JAMA 2008;300:2798-2799.

-15 Yun YH, Park YS, Lee ES, Bang SM, Heo DS, Park SY, You CH, West K: Validation of the Korean version of the EORTC QLQ-C30. Qual Life Res 2004;13:863-868.

16 Zhang H, Ma Y, Wang L, Zhang H: Effect of early palliative care on quality of life in patients with non-smallcell lung cancer. Curr Oncol 2018;25:e54-58.

17 Leung CM, Wing YK, Kwong PK, Lo A, Shum K: Validation of the Chinese-Cantonese version of the hospital anxiety and depression scale and comparison with the Hamilton Rating Scale of Depression. Acta Psychiatr Scand 1999;100:456-461.

18 Kroenke K, Spitzer RL, Williams JB: The PHQ-9: validity of a brief depression severity measure. J Gen Intern Med 2001;16:606-613.

19 Braga M, Gianotti L, Vignali A, Di Carlo V: Immunonutrition in gastric cancer surgical patients. Nutrition 1998;14:831-835.

-20 Shim H, Cheong JH, Lee KY, Lee H, Lee JG, Noh SH: Perioperative nutritional status changes in gastrointestinal cancer patients. Yonsei Med J 2013;54:1370-1376.

21 Yamada N, Koyama H, Hioki K, Yamada T, Yamamoto M: Effect of postoperative total parenteral nutrition (TPN) as an adjunct to gastrectomy for advanced gastric carcinoma. Br J Surg 1983;70:267-274.

$\checkmark 22$ Hye Un Kim JBC, Choong Bai Kim: The Comparison between Early Enteral Nutrition and Total Parenteral Nutrition after Total Gastrectomy in Patients with Gastric Cancer: The Randomized Prospective Study. Korean J Gastroenterol 2012;59:407-413.

23 Culine S, Chambrier C, Tadmouri A, Senesse P, Seys P, Radji A, Rotarski M, Balian A, Dufour P: Home parenteral nutrition improves quality of life and nutritional status in patients with cancer: a French observational multicentre study. Support Care Cancer 2014;22:1867-1874.

24 Chandra RK: Nutrition and the immune system: an introduction. Am J Clin Nutr 1997;66:460S-463S.

25 Valdes-Ramos R, Benitez-Arciniega AD: Nutrition and immunity in cancer. Br J Nutr 2007;98:S127-132.

26 Dias Rodrigues V, Barroso de Pinho N, Abdelhay E, Viola JP, Correia MI, Brum Martucci R: Nutrition and Immune-Modulatory Intervention in Surgical Patients With Gastric Cancer. Nutr Clin Pract 2017;32:122129.

-27 Huang D, Sun Z, Huang J, Shen Z: Early enteral nutrition in combination with parenteral nutrition in elderly patients after surgery due to gastrointestinal cancer. Int J Clin Exp Med 2015;8:13937-13945. 